\title{
RADIATION SHIELDING OF THE FERMILAB 16 GEV PROTON DRIVER*
}

\author{
N. V. Mokhov ${ }^{\dagger}$, A. I. Drozhdin, O. E. Krivosheev, FNAL, Batavia, IL 60510, USA
}

\section{Abstract}

The radiation transport analysis in the proposed Fermilab 1.2 MW Proton Driver (PD) [1] is fundamentally important because of the impact on machine performance, conventional facility design, maintenance operations, and related costs. The strategy adopted in the PD design is that the beam losses in the machine are localized and controlled as much as possible via the dedicated beam collimation system, with a high loss rate localized in that section and drastically lower uncontrolled beam loss rate in the rest of the lattice. Results of thorough Monte Carlo calculations of prompt and residual radiation in and around the PD components are presented for realistic assumptions and geometry under normal operation and accidental conditions. This allowed one to conduct shielding design and analysis to meet regulatory requirements [2] for external shielding, handson maintenance and ground-water activation.

\section{REGULATORY REQUIREMENTS}

1. Prompt radiation: the criterion for dose rate in non-controlled areas on accessible outside surfaces of the shield is $0.05 \mathrm{mrem} / \mathrm{hr}$ at normal operation and $1 \mathrm{mrem} / \mathrm{hr}$ for the worst case due to accidents [3]. Currently, the Fermilab Radiological Control Manual (FRCM) [3] requires that the machine designers describe and justify what a possible "credible worst case accident" is, and design the shielding — or modify operation of the machineaccordingly.

2. Hands-on maintenance: residual dose rate of $100 \mathrm{mrem} / \mathrm{hr}$ at $30 \mathrm{~cm}$ from the component surface, after 100 day irradiation at $4 \mathrm{hrs}$ after shutdown. Averaged dose rate should be $\leq 10-20 \mathrm{mrem} / \mathrm{hr}$.

3. Ground-water activation: do not exceed radionuclide concentration limits $C_{i, r e g}$ of $20 \mathrm{pCi} / \mathrm{ml}$ for ${ }^{3} \mathrm{H}$ and $0.4 \mathrm{pCi} / \mathrm{ml}$ for ${ }^{22} \mathrm{Na}$ in any nearby drinking water supplies. The sum $C_{t o t}$ of the fractions of radionuclide contamination (relative to regulatory limits $C_{i, \text { reg }}$ ) must be less than one for all radionuclides. A corresponding hadron flux above $20 \mathrm{MeV}$ immediately outside the tunnel wall is $\Phi_{h}^{0}=3850 \mathrm{~cm}^{-2} \mathrm{~s}^{-1}$ for a NuMI-like environment [2]. It can be noticeably higher in dolomite or the Fermilab Booster location.

Additionally, one assumes the accumulated dose of $20 \mathrm{Mrad} / \mathrm{yr}$ or $400 \mathrm{Mrad}$ over 20 years lifetime in the hot spots of machine components as a radiation damage limit for such materials as epoxy and cable insulation.

\footnotetext{
* Work supported by the Universities Research Association, Inc., under contract DE-AC02-76CH03000 with the U. S. Department of Energy.

†mokhov@fnal.gov
}

\section{RADIATION ANALYSIS}

\subsection{Normal Operation and Beam Accident}

The shielding analysis for the beam transport lines, arcs and long straight sections is performed both for normal operation and for accidental beam loss. The simplest operational scenario is a $1 \mathrm{~W} / \mathrm{m}$ beam loss rate distributed uniformly along the beam line. A realistic one is based on the beam loss distributions calculated with a beam collimation system which provides the average rates in the arcs of about $0.2 \mathrm{~W} / \mathrm{m}$ at the top energy and less than $0.05 \mathrm{~W} / \mathrm{m}$ at injection. For the worst case catastrophic incredible accident one assumes a loss of the full 1.2 MW of beam at a single point. The worst credible accident limits the amount of beam lost to $0.1 \%$ of that in the incredible case.

\subsection{Tunnel Shielding}

The MARS 14 code system [4] is used to perform all the calculations in this study. A new interface library has been developed which allows one to read and build a complex machine geometry directly from the MAD lattice description. Realistic beam loss distributions are used as a source term for normal operation wherever they are available. A simplest operational scenario with a $1 \mathrm{~W} / \mathrm{m}$ beam loss rate is assumed otherwise. Local shielding is provided around the components in all cases where hands-on maintenance limits on the component outer surface or radiation load to ground water around the tunnel walls in this region are exceeded. This equalizes (to some extent) the source term for the dirt shielding calculation around the entire machine. For accidental beam loss a point-like loss of $1.62 \times 10^{18}$ protons for an hour (incredible accident) and $0.1 \%$ of that (credible accident) are considered. The maximum thickness is put into the design as the tunnel shielding in that part of the machine.

The dose on the outer shielding surface depends on the beam energy in a complex way. Assuming a quasilocal beam loss in the magnet, the dose equivalent was calculated with MARS14 as a function of dirt thickness $\left(\rho=2.24 \mathrm{~g} / \mathrm{cm}^{3}\right)$ outside the tunnel walls. Fig. 1 shows this dependence for a $400 \mathrm{MeV}$ beam (injection), for two intermediate energies of 3 and $8 \mathrm{GeV}$, and for the top beam energy. The dose at high energies scales as $\mathrm{E}^{\alpha}$, where $\alpha$ is about 0.8 , while $\alpha \geq 1$ at $\mathrm{E} \leq 1 \mathrm{GeV}$.

For the $16 \mathrm{GeV} 15 \mathrm{~Hz} \mathrm{PD}$ with $3 \times 10^{13}$ circulating protons, the dose which corresponds to the $1 \mathrm{mrem}$ limit for the worst case point-like loss of $1.62 \times 10^{18}$ protons for an hour is $D_{0}=6.18 \times 10^{-24} \mathrm{~Sv}$ per proton $(1 \mathrm{~Sv}=100 \mathrm{Rem})$, requiring about 28 feet of the dirt shielding around the arc tunnel. With a loss of $0.1 \%$ of the above the shield is 18.5 feet. 


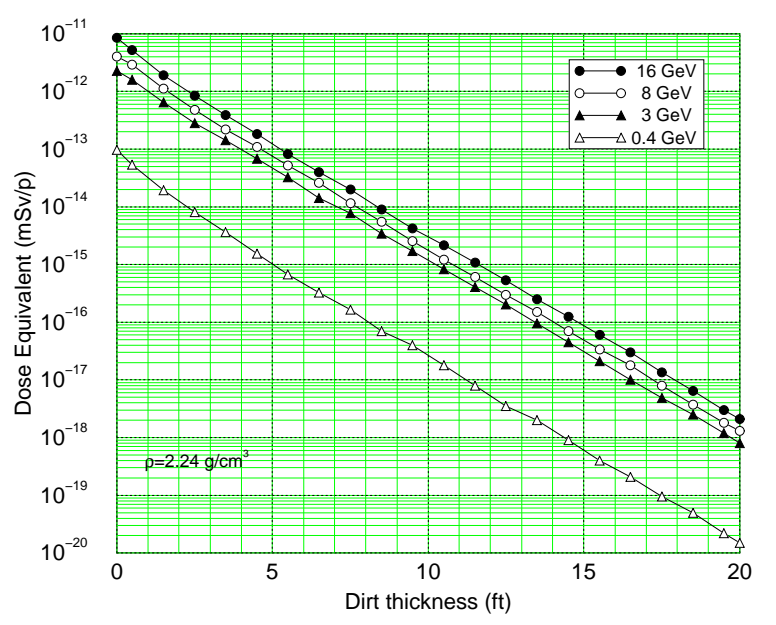

Figure 1: Prompt dose equivalent $v s$ dirt thickness around the tunnel at a point-like proton loss at four energies.

\section{BEAM TRANSPORT LINES}

From the standpoint of machine reliability, a credible accident is defined for beam transport lines as a point-like loss of the full beam continuing for one second during a given one hour period of operations, resulting in $N_{A}(\mathrm{p} / \mathrm{sec})$ lost in a beam-line element. Lateral shielding of thickness $t_{A}$ must provide attenuation of the dose at non-controlled areas on accessible outside surfaces of the shield to $1 \mathrm{mrem} / \mathrm{hr}$. For normal operation of the beam transport lines, we assume at this stage $0.1 \%$ loss over the line length, resulting in a uniform beam loss along a beam line at a $N_{O}(\mathrm{p} / \mathrm{m} / \mathrm{sec})$ rate. Lateral shielding of thickness $t_{O}$ must provide attenuation of the dose at non-controlled areas on accessible outside surfaces of the shield to $0.05 \mathrm{mrem} / \mathrm{hr}$. Material of the lateral shielding outside the tunnel walls is assumed to be Fermilab wet dirt of density $\rho=2.24 \mathrm{~g} / \mathrm{cm}^{3}$.

At injection, accidental $0.4-\mathrm{GeV}$ beam loss of $N_{A}=4.95 \times 10^{14}(\mathrm{p} / \mathrm{sec})$ requires $t_{A}=10.5$ feet of dirt. Operational $0.4-\mathrm{GeV}$ beam loss of $N_{O}=1.65 \times 10^{9}(\mathrm{p} / \mathrm{m} / \mathrm{sec})$ $=0.106 \mathrm{~W} / \mathrm{m}$ along a $300-\mathrm{m}$ long injection beam line requires $t_{O}=9.5$ feet of dirt. Assuming a safety factor of 3 , the thickness of dirt shielding above the $0.4-\mathrm{GeV}$ injection beam line is 12 feet. Phase II ( $4 \mathrm{MW}, 1 \mathrm{GeV})$ will require about 15.25 feet of dirt.

At extraction, accidental $16-\mathrm{GeV}$ beam loss of $N_{A}=4.5 \times 10^{14}(\mathrm{p} / \mathrm{sec})$ requires $t_{A}=17$ feet of dirt. Operational $16-\mathrm{GeV}$ beam loss of $N_{O}=4.5 \times 10^{8}(\mathrm{p} / \mathrm{m} / \mathrm{sec})$ $=1.152 \mathrm{~W} / \mathrm{m}$ along a $1000-\mathrm{m}$ long extraction beam line requires $t_{O}=14.5$ feet of dirt. Assuming a safety factor of 3 , the thickness of dirt shielding above the $16-\mathrm{GeV}$ extraction beam line is 18.5 feet. Phase II (4 MW) will require about 20 feet of dirt.

\section{ARCS}

The full arc lattice in a rectangular tunnel embedded into wet Fermilab dirt is implemented into the MARS calculation model. The tunnel width is 16 feet, its height is 9 feet, the concrete walls are 15-inch thick, ceiling and floor are 30inch thick. Cable trays are positioned at the ceiling in the left and right corners of the cross-sections.

Even with the beam lost uniformly along the arc lattice, there are pronounced peaks of radiation field around the long bare beam pipes. Fig. 2 shows hadron flux distribution across the lattice elements, tunnel, its walls and first layers of the surrounding dirt at such a peak. Around the magnets - due to absorption of radiation in their materialthe flux and, as a result, all other radiation values are several times lower. In the worst case, the maximum flux immediately outside of the tunnel walls can exceed a limit for ground-water activation up to a factor of 5 to 8 . This would imply that either the beam loss rate in such a region should be kept below $0.15-0.2 \mathrm{~W} / \mathrm{m}$ or these regions would require local shielding or thicker walls.

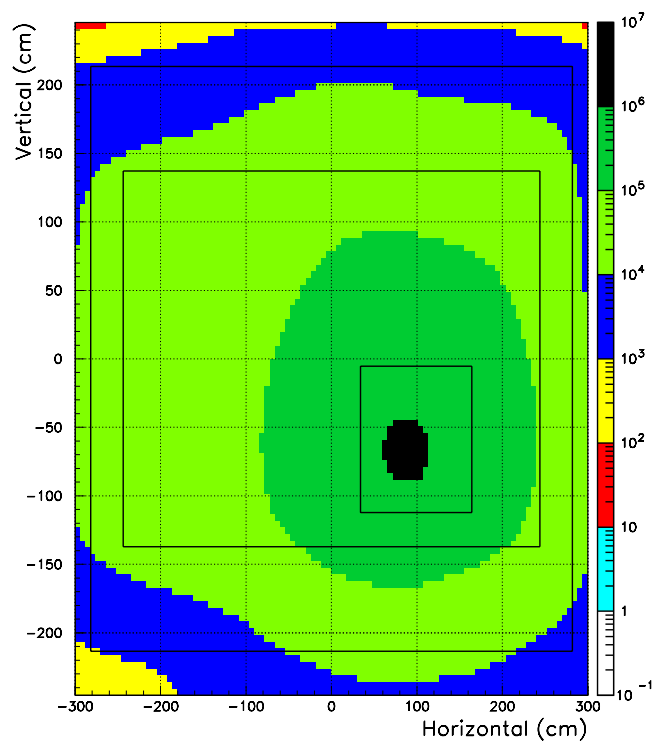

Figure 2: Hadron $(\mathrm{E}>20 \mathrm{MeV})$ isoflux $\left(\mathrm{cm}^{-2} \mathrm{~s}^{-1}\right.$ at $1 \mathrm{~W} / \mathrm{m}$ ) in the arc tunnel cross-section at a long drift.

Despite variation in realistic beam loss distribution along the lattice and remembering the fact that the shield thickness is driven by accidental beam loss which can take place in an arbitrary lattice location, a uniform shielding design along the arcs is suggested. With the point-like accidental loss of $0.1 \%$ of the 1 -hour beam intensity at $16 \mathrm{GeV}$, the shield thickness required is 18.5 feet of Fermilab wet dirt. With the uniformly distributed beam loss rate of $1 \mathrm{~W} / \mathrm{m}$ in the magnets-which is equivalent to about $3.9 \times 10^{8} \mathrm{p} / \mathrm{m} / \mathrm{s}$ lost at $16 \mathrm{GeV}$ - the dirt shielding thickness needed to reduce the dose to $0.05 \mathrm{mrem} / \mathrm{hr}$ is $\sim 14$ feet. Assuming a safety factor of 3 , the thickness of dirt shielding above the arcs, driven by accidental loss, is 20 feet. Phase II (4 MW) will require about 21.5 feet of dirt.

Fig. 3 shows annual dose distributions in the arc crosssection at a beam loss peak in a dipole. The maximum dose accumulated in the coils is about $2 \mathrm{Mrad} / \mathrm{yr}$ at a $1 \mathrm{~W} / \mathrm{m}$ beam loss rate which is acceptable with use of appropriate mate- 


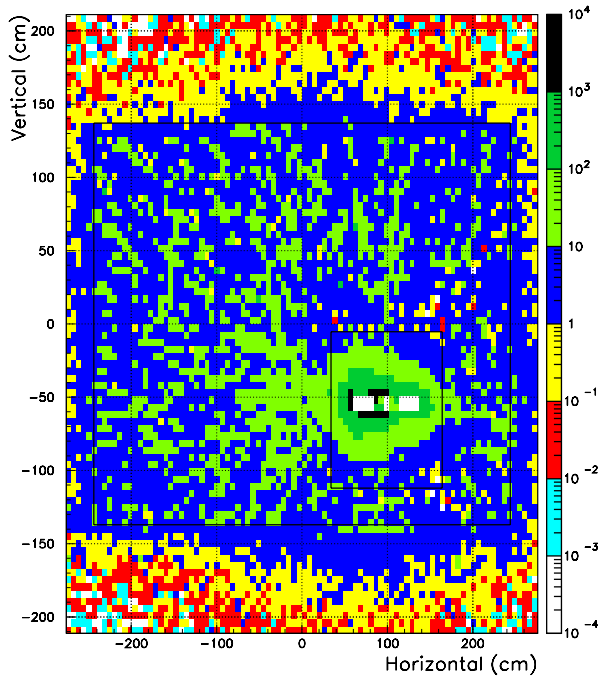

Figure 3: Isodose distribution ( $\mathrm{krad} / \mathrm{yr}$ at $1 \mathrm{~W} / \mathrm{m})$ in the arc tunnel cross-section at peak at a dipole magnet.

rials for insulation. The maximum dose at cable locations is about $0.01 \mathrm{Mrad} / \mathrm{yr}$ around the hot spots in the magnets, and is about $0.1 \mathrm{Mrad} / \mathrm{yr}$ around long bare beam pipes at the same beam loss rate.

Calculated peak residual dose rates near the bare beam pipes exceed the design goal for hot regions of $100 \mathrm{mrem} / \mathrm{hr}$, being noticeably lower near the magnets due to significant absorption of soft photons in the dipole and quadrupole materials. Hands-on maintenance criterion gives about $3 \mathrm{~W} / \mathrm{m}$ for a tolerable maximum beam loss rate in the lattice elements, except for the long bare beam pipes where one should decrease the loss rate to $0.25 \mathrm{~W} / \mathrm{m}$ to reduce the dose to $100 \mathrm{mrem} / \mathrm{hr}$. One needs further reduction to bring the dose down to a good practice value of about $10-20 \mathrm{mrem} / \mathrm{hr}$. Alternatively, one can think of providing simple shielding around the bare beam pipes. With these measures, the above problem with ground water activation —if it exists at the site-is solved automatically.

\section{LONG STRAIGHT SECTIONS}

The P20 long straight section includes the injection system and the collimators, which intercept about $99 \%$ of beam loss, therefore being the hottest region in the machine (Fig. 4). The secondary copper collimators are $0.5-\mathrm{m}$ long and $44 \times 44 \mathrm{~cm}^{2}$ transversely. They are the hottest spots, with beam loss rates of several $\mathrm{kW} / \mathrm{m}$. Local steel shielding is $2.5 \mathrm{~m}$ long and about $1 \mathrm{~m}$ thick laterally around all secondary collimators, dipoles and quadrupoles downstream. Residual dose rates on the outer surface of the proposed shielding do not exceed 20 to $100 \mathrm{mrem} / \mathrm{hr}$ at standard conditions. The tunnel wall thickness should be increased from that in the arcs by one foot. With such a shield, radiation levels outside the tunnel wall are very close to those in the arcs. Therefore, the same external shielding design both for normal operation and beam accident is applied. With a safety factor of 3 , the thickness of dirt shielding above the P20 long straight section is 20 feet, increased to about 21.5 feet at Phase II (4 MW). The maximum dose accumulated in the collimator cores is several hundred Mrad/yr. The maximum annual dose at cable locations is several tens of krad per year and can be as high as 0.1-0.3 Mrad/yr around the open drifts.

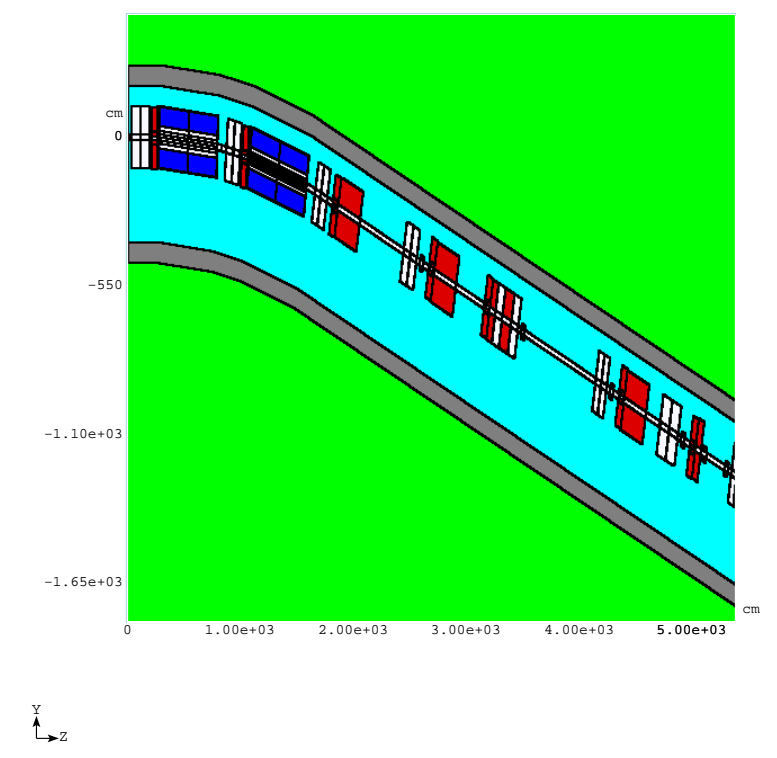

Figure 4: Longitudinal view of the collimation region with the proposed shielding as implemented into the MARS 14 calculation model.

Extraction from the PD will be one-turn fast extraction. In order to reduce the extraction loss in Stage 1, there will be a 7-bucket notch in a train of 126 bunches. Therefore, there will be little loss at the extraction septum. In Stage 2, this notch is not needed due to a large bunch spacing (132 ns). When the machine is well tuned, the extraction loss can be as low as the order of $10^{-4}$, which has been achieved at the ISIS. As for the RF cavities with large apertures, our calculations show no noticeable beam loss in those regions. The above implies that no local shielding is needed in the P40 and P60 long straight sections. At this stage, shielding design and radiation requirements in these regions are assumed the same as in the arcs.

\section{REFERENCES}

[1] "The Proton Driver Design Study", Fermilab-TM-2136 (2001).

[2] O. E. Krivosheev and N. V. Mokhov, Proc. of the 7th ICFA Mini-Workshop on Beam Halo and Scraping, Lake Como, WI, September 13-15, 1999, Fermilab-Conf-00/185, Fermilab-Conf-00/192 (2000).

[3] "Fermilab Radiological Control Manual", Article 236, http://www-esh.fnal.gov/FRCM/.

[4] N. V. Mokhov, "The MARS Code System User's Guide", Fermilab-FN-628 (1995); N. V. Mokhov and O. E. Krivosheev, "MARS Code Status", Fermilab-Conf00/181 (2000). http://www-ap.fnal.gov/MARS/. 